\title{
EDUCAÇÃO AMBIENTAL E AS TRILHAS: CONTEXTO PARA A SENSIBILIZAÇÃO AMBIENTAL ${ }^{1}$
}

\author{
Mariana Cristina da Cunha Souza ${ }^{2}$
}

Resumo: As práticas e atividades que caracterizam a Educação Ambiental (EA) têm-se valorizado enquanto alternativa educativa na construção de valores, que levem à sensibilização da coletividade social para as questões ambientais, de maneira crítica e reflexiva. Sendo a finalidade da EA a de sensibilizar ambientalmente, torna-se necessária a formatação de metodologias coerentes para que este processo se torne efetivo nas pessoas. Nesta perspectiva, as trilhas ecológicas e/ou interpretativas são adotadas para algumas realidades de estudo, enquanto procedimento diferencial em processos de EA e de sensibilização por meio das atividades características desta. Infere-se que no contato com o meio natural há um despertar do homem para reflexões sobre a necessidade de valorização ambiental e, com a presença de um condutor que instigue o pensamento crítico em meio à caminhada, torna-se possível tecer considerações sobre a problemática ambiental congregando outros campos do saber, como a econômica, política e a própria dimensão social. Diante disto, o presente trabalho tem como objetivo abordar a temática da EA e demonstrar de que maneira as trilhas ecológicas e/ou interpretativas constituem-se em metodologia eficiente e de qualidade para $o$ ato de educar ambientalmente.

Palavras-chave: Educação Ambiental; Trilhas ecológicas e/ou interpretativas; Sensibilização Ambiental; ESEC-Caiuá-PR.

\footnotetext{
${ }^{1}$ Artigo desenvolvido durante a graduação em Turismo, a partir dos resultados obtidos com a pesquisa de iniciação científica, financiada pela Fundação de Amparo à Pesquisa do Estado de São Paulo (FAPESP) e intitulada "Educação Ambiental em Unidades de Conservação: Análise dos processos desenvolvidos pela Estação Ecológica do Caiuá/PR".

${ }^{2}$ Mestranda pelo programa de Pós-Graduação em Geografia da FCT-UNESP, Campus de Presidente Prudente-SP. E-mail: mccunhasouza@hotmail.com.
} 


\section{Introdução}

A discussão sobre a crise ambiental, cuja origem se relaciona diretamente a uma crise social, foi se disseminando pelo mundo, prioritariamente, durante as últimas quatro décadas. $O$ debate a cerca dos problemas ambientais - ocupação urbana em áreas de risco, aumento da ocorrência de enchentes devido à impermeabilidade do solo e o manejo inadequado dos resíduos sólidos, a falta de saneamento básico no espaço da cidade, a carência de vegetação urbana e etc.- tem sido propiciado por estudiosos das mais diversas áreas do conhecimento.

Tais discussões buscam relacionar os impactos negativos causados ao ambiente a partir das ações de um agente social específico, o ser humano. $O$ homem, em sua coletividade social, influenciado por contextos históricos específicos vincula-se a uma visão de mundo calcada na racionalidade e nos pressupostos do sistema social e político capitalista. Além de acentuar diferenciais sociais, este modelo ao incentivar a produção e o consumo desenfreado de mercadorias, contribui diretamente para a efetivação das mazelas ambientais já presentes na paisagem urbana (DIAS, 2004).

Neste contexto, o reconhecimento da complexa e direta relação entre o modo de produção capitalista e as práticas da vida contemporânea com a manutenção dos problemas ambientais, leva a compreensão de que se trata de um conflito do próprio sentido da vida e da existência humana na superfície terrestre. Portanto, torna-se fundamental uma transformação no modo de pensar e agir social, que transforme igualmente a racionalidade exercida sobre o meio natural e seus recursos (MEDINA, 1999).

É em busca disso que surgem os movimentos de algumas camadas sociais específicas reivindicando reflexões a cerca de como o ambiente e seus recursos têm sido apropriados e explorados sem planejamento e de forma degradante. Tais movimentos contribuem para a projeção de ações, planos e medidas na intenção de se minimizar os impactos negativos causados ao meio.

Historicamente, pode-se citar a Primeira Conferência Mundial sobre Meio Ambiente Humano e Desenvolvimento realizada em 1972 na cidade sueca de Estocolmo. Esta conferência mostrou que a realidade ambiental mundial era preocupante e que os problemas existentes levariam a escassez de recursos essenciais à sobrevivência humana e dos outros animais. Durante esta conferência surgiram as primeiras propostas para um manejo e "exploração conscientes" dos recursos naturais (SERRANO; BRUNHS, 2000).

Tratando dos problemas ambientais como um coletivo global, a conferência representou e ainda representa um marco histórico na discussão sobre a problemática ambiental, uma vez que aproximou os países mais desenvolvidos dos menos desenvolvidos em assuntos referentes à preservação e conservação ambiental. Vale salientar que durante o encontro recomendou-se o estabelecimento de um programa internacional que fosse 
pautado em Educação Ambiental, acreditando que a mesma seria uma alternativa viável para se educar ambientalmente a sociedade (CASCINO, 2007; DIAS, 2004).

A Educação Ambiental proposta estará voltada à sensibilização das pessoas para as questões relacionadas ao ambiental, à sua conservação e preservação. A EA buscará uma transformação no modo de pensar e agir social, visando à tomada de consciência crítica no entendimento e compreensão da realidade que se apresenta e a complexidade que a envolve. De acordo com Paulo Freire (1980), a educação deve proporcionar a tomada de consciência e de pensamento crítico, alterando o modo com que a sociedade toma suas decisões, libertando-se do que lhe é imposto. É por este viés que a EA trilhará o seu caminho e será estruturada.

\section{Contextos para a Educação Ambiental}

A Educação ambiental, enquanto meio para se educar ambientalmente emergiu concomitantemente à disseminação do debate sobre as questões ambientais pelo mundo. Hoje, as atividades que a caracterizam são tidas como instrumentos fundamentais de transformação do pensar e do agir social (DIAS, 2004).

As práticas e atividades de EA carecem de planejamento e estruturação prévia, todavia, nota-se que em muitas realidades abordadas em alguns estudos, tal educação tem sido trabalhada de forma incoerente e divergente. Neste caso, pode-se pensar que a EA ainda esteja vinculada à maneira pela foi compreendida inicialmente, ou seja, como uma educação informativa voltada especificamente para o conhecimento e não entendimento e reflexão, dos processos naturais físicos e biológicos do ambiente. Porém, é fundamental esclarecer que esta abordagem é superficial, uma vez que educar ambientalmente vai além do conhecimento dos processos físicos e biológicos. A EA é um processo no qual as pessoas são incentivadas a pensar reflexivamente e criticamente (CASCINO, 2007).

Como mencionado, pensar em educação ambiental significa pensar no próprio ato de se educar para e com a natureza; refletindo sobre o real papel desempenhado pelo homem, a partir de suas práticas, na produção do lugar onde se insere (MEDINA, 1999).

Tais considerações justificam-se também pelo o que foi mencionado durante o Primeiro Congresso Mundial de Educação Ambiental, realizado em 1977, na cidade de Tbilisi, Geórgia. Estabeleceu-se que a educação ambiental era:

[...] o resultado de uma reorientação e articulação de diversas disciplinas e experiências educativas que facilitam a percepção integrada do meio ambiente, tornando possível uma ação mais racional e capaz de responder às necessidades sociais (UNESCO apud DIAS, 2004, p.105). 
A definição citada ainda aborda outra característica fundamental das práticas de EA que é a questão da interdisciplinaridade. A interdisciplinaridade é compreendida neste trabalho não apenas como $\mathrm{o}$ ato de comparar $\mathrm{e}$ relacionar "coisas" parecidas, mas como a possibilidade de dialogar e intercambiar conhecimento na diferença, congregando a riqueza da diversidade (CASCINO, 2007).

Esta interdisciplinaridade estará presente no relatório formatado pela primeira-ministra da Noruega Sra. Gro Brundtland, em 1983, quando a mesma reuniu-se com especialistas ambientais de diferentes áreas do conhecimento, elaborando um documento que teve como objetivo analisar as principais informações referentes ao desenvolvimento e ao meio ambiente. $O$ relatório, publicado quatro anos mais tarde em 1987 ficou conhecido como Nosso Futuro Comum e tornou-se referência para algumas discussões durante a Conferência Sobre o Meio Ambiente e o Desenvolvimento, a Rio-92 realizada na cidade brasileira do Rio de Janeiro (CASCINO, 2007).

Nesta Conferência definiu-se educação ambiental como:

[...] um processo permanente no qual os indivíduos e a comunidade tomam consciência do seu meio ambiente e adquirem conhecimentos, valores, habilidades, experiências e determinação que os tornem aptos a agir e resolver problemas ambientais, presentes e futuros (DIAS, 2004, p.523).

A Rio-92 trouxe para o Brasil representantes de 170 países que em conjunto verificaram os avanços adquiridos no campo ambiental desde a Conferência de Estocolmo, realizada em 1972. Ainda neste encontro, foram propostas estratégias para que as nações alcançassem o desenvolvimento com bases na sustentabilidade que adjetivando o desenvolvimento econômico, seria entendido como aquele desenvolvimento que atende as necessidades das gerações atuais sem comprometer as necessidades das gerações futuras, respeitando o equilíbrio social e ecológico e, principalmente, as necessidades dos mais pobres (DIAS, 2004).

O principal legado da conferência de 1992 foi o documento conhecido como a Agenda-21, no caso, um plano de ação que orientaria 0 desenvolvimento dos países signatários ao longo do século XXI. O documento que possui quarenta capítulos trata de assuntos diversos e relaciona desde as dimensões econômica e social às dimensões cultural e ambiental. Ainda de acordo com o mesmo, cada Estado se responsabilizaria por formatar suas próprias metodologias para 0 desenvolvimento de práticas ambientais educativas (REIGOTA, 2006).

Logo, no caso brasileiro, segundo o Art. 1ํ da Lei № 9.795 de 27 de abril de 1999 que dispõe sobre a Educação Ambiental e institui a Política Nacional de Educação Ambiental (PNEA), a EA é conceituada como: 
Os processos por meio dos quais o indivíduo e a coletividade constroem valores sociais, conhecimentos, habilidades, atitudes e competências voltadas para a conservação do meio ambiente, bem de uso comum do povo, essencial à sadia qualidade de vida e sua sustentabilidade (BRASIL, 1999). seriam:

No artigo $4^{\circ}$ desta lei disserta-se sobre os princípios básicos da EA, que

I - o enfoque humanista, holístico, democrático e participativo;

II - a concepção do meio ambiente em sua totalidade, considerando a interdependência entre o meio natural, o socioeconômico e o cultural, sob o enfoque da sustentabilidade;

III - o pluralismo de ideias e concepções pedagógicas, na perspectiva da inter, multi e transdisciplinaridade;

IV - a vinculação entre a ética, a educação, o trabalho e as práticas sociais;

$\mathrm{V}$ - a garantia de continuidade e permanência do processo educativo;

VI - a permanente avaliação crítica do processo educativo;

VII - a abordagem articulada das questões ambientais locais, regionais, nacionais e globais;

VIII - o reconhecimento e o respeito à pluralidade e à diversidade individual e cultural (PNEA, 1999).

Para Enrique Leff (2007, p. 59) "La educación ambiental es el proceso dialógico que fertiliza lo real y abre las posibilidades para que llegue a ser lo que aún no es". Diante disto, reafirmam-se as contribuições que o desenvolvimento planejado e coerente de atividades de educação ambiental tem no processo de transformação do pensar e agir social e na tomada de consciência e visão de mundo críticos.

\section{Educação Ambiental Formal e Não- Formal}

Considerando o que foi instituído na Lei no 9.795 de 1999, pode-se falar em duas formas de se trabalhar com a Educação Ambiental que é a formal e a não formal (PNEA, 1999).

Segundo o Art. 9 compreende-se por educação ambiental formal aquela desenvolvida no âmbito dos currículos das instituições de ensino público e privado, congregando:

I - educação básica:

a) educação infantil;

b) ensino fundamental e c) ensino médio;

II - educação superior; III - educação especial;

IV - educação profissional;

V - educação de jovens e adultos. 
Art. 10. A educação ambiental será desenvolvida como uma prática educativa integrada, contínua e permanente em todos os níveis e modalidades do ensino formal.

$\S 1^{\circ}$ A educação ambiental não deve ser implantada como disciplina específica no currículo de ensino;

$\S 2^{\circ}$ Nos cursos de pós-graduação, extensão e nas áreas voltadas ao aspecto metodológico da educação ambiental, quando se fizer necessário, é facultada a criação de disciplina específica;

$\S 3^{\circ}$ Nos cursos de formação e especialização técnico-profissional, em todos os níveis, deve ser incorporado conteúdo que trate da ética ambiental das atividades profissionais a serem desenvolvidas;

Art. 11. A dimensão ambiental deve constar dos currículos de formação de professores, em todos os níveis e em todas as disciplinas;

Parágrafo único. Os professores em atividade devem receber formação complementar em suas áreas de atuação, com o propósito de atender adequadamente ao cumprimento dos princípios e objetivos da Política Nacional de Educação Ambiental;

Art. 12. A autorização e supervisão do funcionamento de instituições de ensino e de seus cursos, nas redes pública e privada, observarão o cumprimento do disposto nos arts. 10 e 11 desta Lei.

Assim, a EA Formal caracteriza-se por ações realizadas nas dependências da sala de aula, fundamentando-se sob os parâmetros curriculares de suas instituições escolares. A abordagem formal possui caráter contínuo e permanente, em todos os níveis e modalidades do ensino formal, característica importante quando se pensa em processos de educação ambiental - são exemplos de práticas da EA Formal a comemoração da Semana do Meio Ambiente ou também o Dia da Árvore, no qual, geralmente, se planta uma árvore, etc. -, entretanto, tais práticas são ações pontuais que mesmo tendo sua importância, não são determinantes para o processo de sensibilização, uma vez que não apresentam uma continuidade efetiva (LEONARDI, 1999; PNEA, 1999).

Já de acordo com o Art. $13^{\circ}$ da mesma lei, compreendem-se como Educação Ambiental Não Formal as ações e práticas educativas voltadas à sensibilização da coletividade sobre as questões ambientais e à sua organização e participação na defesa da qualidade ambiental.

Parágrafo único. O Poder Público, em níveis federal, estadual e municipal, incentivará:

I - a difusão, por intermédio dos meios de comunicação de massa, em espaços nobres, de programas e campanhas educativas, e de informações acerca de temas relacionados ao meio ambiente;

II - a ampla participação da escola, da universidade e de organizações não governamentais na formulação e execução de programas e atividades vinculadas à educação ambiental Não Formal; 
III - a participação de empresas públicas e privadas no desenvolvimento de programas de educação ambiental em parceria com a escola, a universidade e as organizações não governamentais;

IV - a sensibilização da sociedade para a importância das unidades de conservação;

V - a sensibilização ambiental das populações tradicionais ligadas às unidades de conservação;

VI - a sensibilização ambiental dos agricultores; VII - o Ecoturismo.

A EA Não Formal caracteriza-se, portanto, pelas práticas em locais fora do ambiente escolar, a partir de metodologias e abordagens distintas da EA Formal e, de certa forma, menos estruturadas do que esta. As atividades de educação ambiental não formal são bastante realizadas por ONGs, empresas, associações de classe, etc. sendo características as atividades desenvolvidas com o público visitante de áreas verdes, como os parques, unidades de conservação; os encontros e cursos que discutem questões de ordem ambiental; os eventos organizados por instituições governamentais ligadas ao planejamento ambiental, além do desenvolvimento de pesquisas e etc. (LEONARDI, 1999; PNEA, 1999).

Tanto a EA Formal quanto a EA Não Formal possuem parâmetros que orientam o processo educativo. Segundo Butzke, Pereira e Noebauer (2007, p.8), estes se resumem em:

Sensibilização/mobilização: entende-se como 0 conhecimento genérico que é transmitido aos envolvidos. Trata-se, em grande parte, da divulgação dos programas e das atividades, bem como dos conceitos ambientais. É uma ação desenvolvimento e motivação das pessoas, pois é "aqui que as ganha ou as perde".

Percepcão da comunidade/conhecimento: entende-se como conhecimento específico, geralmente para um público-alvo ou para um aspecto ambiental especial. Estes conhecimentos são elaborados por técnicos das áreas específicas abordadas.

Participação: aqui se compreende 0 engajamento das pessoas nos programas e nas ações educativas. Pode-se dizer que o objetivo educativo será atingido de fato se as pessoas participarem espontaneamente. Porém, 0 fato delas participarem de qualquer forma, às vezes até por pressão, poderá trazer resultados positivos, pois a repetição constante de um ato acaba gerando adaptação, e esta poderá levar a uma mudança consciente de valores e comportamentos. Sem contar, é claro, que toda ação positiva gera resultados também positivos para a instituição.

Acompanhamento/avaliacão: este é o conjunto de indicadores mais subjetivo de todos, pois dificilmente poderá ser medido numericamente - a não ser pelos resultados obtidos nos programas implantados. Além disto, não se refere 
apenas aquelas ações que objetivem resultados positivos para a instituição, mas sim, refere-se à mudança consciente de cada indivíduo, passando a ter um comportamento diferente na sua relação indivíduo-meio ambiente e sociedade-meio ambiente. É aqui que realmente se pode atingir uma mudança na qualidade de vida das pessoas.

Materiais didáticos: devem ser adequados para orientar 0 trabalho do educador. Os materiais devem contemplar aspectos sobre a realidade dos envolvidos no processo de educação ambiental. Os mesmos não devem apresentar apenas um caráter informativo e ecológico, mas sim, que sejam inclusos temas sociais, econômicos e culturais, reforçando assim as visões reducionistas da questão ambiental.

Mesmo diante de todos os fundamentos mencionados, a EA enfrenta muitos obstáculos e um dos mais significativos relaciona-se aos procedimentos metodológicos, notadamente para EA Não Formal. Há poucas produções científicas que tratam especificamente deste assunto, sobretudo, quanto aos indicadores de avaliação que permitirão inferir o grau de sensibilização que uma atividade ou ação pode gerou na pessoa.

Esta realidade é agravada pela carência de profissionalização dos envolvidos com determinadas atividades, já que os educadores que trabalham e colocam em prática a educação ambiental muitas vezes acabam por contemplar apenas o aspecto físico do ambiente, não trazendo para o debate a reflexão crítica sobre temáticas de cunho social, econômico, cultural e político, indispensáveis na tomada de consciência crítica e de sensibilização para a problemática ambiental. Neste sentido, tem-se o relato de estudiosos sobre a dificuldade encontrada em estabelecer índices e indicadores para atividades de $E A$, uma vez que estas se caracterizam em grande medida pela subjetividade (PEREIRA; BESSA, 2008).

\section{Trilhas Ecológicas e/ou Interpretativas e o processo de sensibilização.}

Tendo em vista a carência de metodologia para o estabelecimento de índices e indicadores que se atentam ao processo de sensibilização ambiental, busca-se a superação deste obstáculo a partir da escolha de ambientes que sejam considerados mais propícios à sensibilização social por meio da participação de atividades de EA. Neste caso, estão abarcadas as trilhas ecológicas e/ou interpretativas. As trilhas são, fundamentalmente, corredores de viagem que foram abertos de uma área a outra, principalmente no meio natural (BIRKBY, 1997 apud MAGRO; TALORA, 2006).

Os motivos que levam uma pessoa a ter contato com uma área natural e a utilizar deste corredor são: pessoas que a utilização da trilha significa uma maneira mais rápida de se chegar ao seu destino e, pessoas que a trilha caracteriza-se como uma forma de apreciação do ambiente natural, é quando 
podem aproveitar cada momento do percurso e do contato com os elementos da natureza (MAGRO; TALORA, 2006).

No caso de estarem localizadas em áreas ambientalmente protegidas, a criação de trilhas ou o aproveitamento de caminhos já abertos em momentos anteriores tem como objetivo proporcionar aos visitantes um aprendizado através do contato com os elementos da natureza. Infere-se que a caminhada em ambientes naturais contribua para uma melhor compreensão do que é o natural, sua importância para a paisagem e para a qualidade ambiental. $O$ contato com elementos naturais incentivam a observação e proporciona momentos de reflexão (RODRIGUES, 2000; CARVALHO; BOÇON, 2004).

As trilhas possuem diferentes percursos e graus de dificuldades, logo, é comum que em trilhas mais longas e com grau de dificuldade mais elevado seja necessária à presença de um guia, que se constituí em elemento chave na construção do saber ambiental no momento deste contato com a natureza. $\mathrm{O}$ guia, além de condicionar a caminhada tem a tarefa de instigar a reflexão das pessoas sobre a importância das áreas protegidas e das questões ambientais (SAMPAIO; GUIMARÃES, 2009).

Diante disso, considera-se que a trilha é metodologia fundamental no processo de sensibilização ambiental, prioritariamente da EA não formal. Esta afirmação justifica-se por se acreditar que este ambiente seja mais propício à sensibilização devido à possibilidade de contato da pessoa com a natureza e, assim, a mesma é condicionada a perceber, observar e analisar o ambiente pelo qual esta de passagem, podendo despertar nela a vontade de preservar e conservr.

\section{Estudo de caso na Estação Ecológica do Caiuá-PR ${ }^{3}$ (ESEC Caiuá-PR).}

Considerando a trilha como metodologia fundamental em processos de sensibilização ambiental, optou-se em analisá-la a partir da pesquisa de iniciação científica desenvolvida na Estação Ecológica do Caiuá-PR (ESECCaiuá, Figura 1), quando notou-se a importância das atividades de EA realizadas no ambiente das trilhas interpretativas. Esta análise foi permitida através da aplicação da técnica de observação participante, acreditando que para a realidade estudada, a mesma possibilitaria interpretações mais reflexivas e representativas do real, como por exemplo, na análise da conduta, do comportamento, durante o processo de aprendizagem dos visitantes etc. (SILVA, 2007).

\footnotetext{
${ }^{3}$ Unidade de Conservação (UC) de Proteção Integral localizada na divisa entre os estados do Paraná e São Paulo e tem como objetivos proteger um dos últimos remanescentes da Floresta Estacional Semidecidual localizada no noroeste do estado do Paraná; proporcionar pesquisas básicas e científicas; possibilitar atividades de EA etc. (IAP, 1997). 


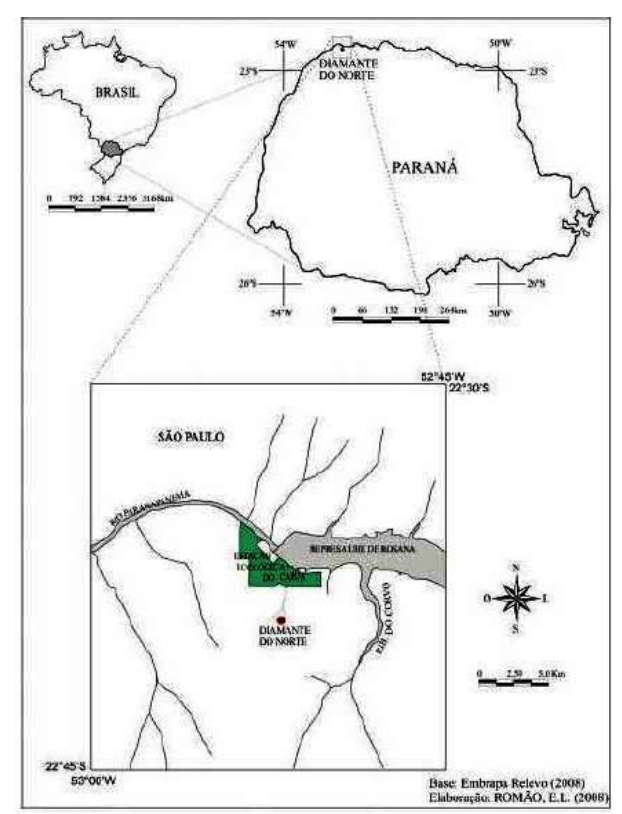

Figura 1: Mapa da localização da Estação Ecológica do Caiuá no Brasil e no Estado do Paraná. Fonte: IAP (1997).

A observação participante contribuiu para a análise de como as trilhas eram trabalhadas na ESEC porque possibilitou um contato aproximado com os grupos visitantes, o acesso a informações fundamentais, principalmente, sobre questões subjetivas que foram extremamente relevantes para os resultados da pesquisa. Entende-se aqui a observação participante como aquela em que os dados e informações são coletados durante a participação do pesquisador no cotidiano do grupo que ele decidiu estudar (BECKER, 1999; MAY, 2004).

$\mathrm{Na}$ referida UC, as trilhas juntamente com a fauna e flora locais, são consideradas as maiores atratividades. $\mathrm{Na}$ área existem quatro trilhas com percursos distintos: a Trilha do Mico, Trilha da Arara, Trilha do Cedro e Trilha da Cachoeira, porém as atividades de EA limitavam-se em grande parte às Trilhas do Cedro e da Arara (IAP, 1997).

Durante a pesquisa, alguns grupos que visitaram a UC foram acompanhados de perto em suas visitas, sobretudo, durante a caminhada nas trilhas ecológico-interpretativas. A caminhada era obrigatoriamente acompanhada pelo guia da ESEC e também, quando possível, pelos voluntários que prestavam serviços na estação. Foi durante estes momentos que se tornou possível observar os grupos no ambiente das trilhas e descobrir que em grande parte das visitas não havia um incentivo a reflexão sobre a importância daquele ambiente para a preservação e conservação da fauna, da flora e etc.. Durante as visitas o guia apenas transmitia algumas informações genéricas, tais como sobre as principais espécies da flora, como a Peroba Rosa e da fauna, como as Araras.

Outra observação que diz respeito às atividades desenvolvidas é que, quando as mesmas ocorriam era no momento posterior à caminhada nas trilhas, ou seja, as dinâmicas de reflexão primordiais para o processo de sensibilização, já que é o momento em que os membros dos grupos podem Revbea, São Paulo, V.9, № 2: 239-253, 2014. 
relatar suas experiências, vivências e percepções advindas através do contato com o ambiente natural durante a caminhada, eram realizadas objetivamente fora do ambiente da trilha, ao invés de dentro e/ou durante a caminhada. O que seria mais benéfico para o processo de sensibilização.

Notou-se que, sendo as atividades de EA relacionadas à caminhada na trilha a principal ferramenta metodológica utilizada pela UC no processo de sensibilização, ressaltou-se a necessidade de uma melhor formatação e estruturação das atividades, uma vez que foi percebido que na UC não havia metodologias de avaliação das práticas realizadas durante as visitas. Logo, buscou-se com a pesquisa construir alguns indicadores que fossem representativos do processo de sensibilização ambiental.

A construção dos indicadores, permitida pela observação dos membros dos grupos durante a socialização de suas experiências e de manifestações comportamentais dos mesmos, levou a constatação de que mesmo com os obstáculos metodológicos já citados sobre a educação ambiental, em algum momento durante a caminhada nas trilhas os visitantes eram sensibilizados, mesmo que de forma imediata.

Como se sabe a sensibilização é fundamental em processos de EA e é através de sua constatação que pode- se dizer que as atividades estão sendo realizadas de maneira coerente ou não. A sensibilização é definida por Pedrini (2007) como um fator um tanto quanto subjetivo para ser avaliado, já que apesar de os membros de um mesmo grupo realizar as mesmas atividades, a percepção, atenção, conhecimentos, saberes, vivências e envolvimento etc., são características particulares de cada pessoa, o que não pode ser quantificado.

Neste sentido é que a observação das dinâmicas realizadas após a caminhada nas trilhas ecológico-interpretativas da Arara e do Cedro e das manifestações corporais levou ao entendimento da sensibilização conseguida através do contato com elementos naturais no ambiente das trilhas. A interpretação, mais especificamente, de alguns elementos como a satisfação, a agitação, os relatos de experiência e a participação, que são abordados individualmente abaixo, foi o diferencial na compreensão da trilha como metodologia significativa para EA.

Inicialmente, considerou-se a satisfacão um índice para avaliar as atividades educativas realizadas porque foi notada a falta de contentamento de alguns visitantes quando estes chegavam a ESEC Caiuá/PR e participavam de uma palestra sobre aspectos informativos da UC. Porém, ao serem encaminhados para a trilha e, principalmente, ao retornarem da caminhada, muitos visitantes aparentavam satisfação e excitação, fato confirmado no momento de socialização das suas vivências e percepções. $O$ momento do relato de experiência e reflexão do visitante é importante porque se acredita que o mesmo seja sincero ao compartilhar sua experiência, influenciada por tudo que vivenciou na UC. Manifestações como estas podem mostrar muito sobre a satisfação do visitante, já que satisfação é algo bastante pessoal. 
A agitacão após as atividades nas trilhas também foi considerada um indicador neste estudo, já que geralmente, quando a pessoa esta em contato com a natureza a tendência é que ela fique mais passiva, ou seja, menos agitada. Desta forma, a agitação seria um indicador de que alguma coisa não foi realizada com sucesso durante as atividades. Entretanto este indicador só será validado através das reflexões do visitante após as atividades. Na ESEC muitas vezes o visitante que não se sentia à vontade para falar para o grupo, podia se expressar também pela escrita, opção viável para os mais tímidos, desde que de acordo com a atividade pós-trilha. Assim, todos tinham a oportunidade de tornar público suas percepções.

Quando o visitante participava das reflexões, expondo suas ideias notouse que esta iniciativa poderia ser também um indicador, o de que ele se sentiu à vontade com o grupo, no ambiente da estação ecológica, durante as atividades tanto que ao final ele busca essa interação com o restante do grupo. Da mesma maneira, o indicador relatos de experiências será confirmado com o posicionamento do visitante no momento do seu discurso. O momento de reflexão é o mais importante na verificação do processo de sensibilização, pois nesta hora, o responsável pela atividade consegue todas as informações necessárias sobre como foi o desenrolar da visita, identificando os pontos fortes e fracos sob a percepção daqueles que participaram das atividades, sendo o foco de sensibilização através delas.

Por fim, a participação que é o indicador que permeia todos os indicadores anteriormente mencionados, já que quando 0 visitante se sensibiliza através das atividades de EA em algum momento ou de alguma forma ele fica muito focado e entusiasmado em participar das reflexões, expondo suas visões, percepções, fazendo perguntas, enfim, interagindo. $O$ Conjunto destes indicadores foi considerado proveitoso e importante para análises efetivas do processo de sensibilização para a realidade estudada na Estação Ecológica do Caiuá-PR.

\section{Considerações Finais}

As discussões sobre a problemática ambiental proporcionou também o debate sobre as questões relacionadas à crise social, política e econômica perpetuada pelo modo de vida baseado nos pressupostos capitalistas. Assim, a Educação Ambiental tornou-se uma alternativa na busca de novos meios de sensibilizar a sociedade para as questões ambientais, levando-a a uma percepção crítica e reflexiva sobre a complexidade vinculada aos problemas que afetam o ambiente nos dias de hoje. A EA aspira uma transformação profunda e efetiva no pensamento e modo de agir social, através da construção de valores e de postura que sejam éticos perante a natureza, onde o ser humano se enxergue como principal agente de transformação ambiental e de degradação do mesmo. 
Diante do que foi destacado neste trabalho, infere-se que em processos de EA, principalmente sob seu aspecto Não Formal, as trilhas ecológicas e/ou interpretativas revelam-se elementares e quando aliadas às dinâmicas de grupo, desenvolvidas de maneira coerente e planejada, torna-se uma das metodologias mais eficazes quando se trata de sensibilizar ambientalmente.

O ambiente da trilha permite uma aproximação efetiva da pessoa com o que é natural, levando-a ao contato com elementos constituintes do meio, muitas vezes não presentes em seu dia-a-dia. $O$ caminho da trilha possibilita uma vivencia e percepção do ambiente e influencia para que a pessoa reflita sobre a importância da natureza e a necessidade de mantê-la conservada e preservada. Vale destacar que as atividades nas trilhas não podem ser apenas uma caminhada sem objetivos, finalidades e fundamentos pré-determinados. É imprescindível o planejamento e correta elaboração das atividades que serão desenvolvidas, já que ficou entendido que o próprio ambiente da trilha já contribui para uma sensibilização mesmo que imediata. Logo, se a caminhada na trilha estiver aliada a atividades que busquem um aprendizado crítico das questões ambientais, certamente haverá uma sensibilização mais significativa por meio desta atividade.

A EA em conjunto ao ambiente da trilha aparece e se firma como metodologia ímpar em processos de sensibilização ambiental, já que permite uma assimilação entre conhecimentos adquiridos e percepções no próprio ambiente natural, propiciando situações e condições mais positivas para reflexões e percepções. A EA não é simples educação informativa, mas processual e como tal visa transformações: de comportamento, de postura, de visão crítica, de conduta ética, etc., de construção de valores éticos que contribuam para o processo de conservação e preservação ambiental. Portanto, considera-se que a educação ambiental e a possibilidade de sensibilização através do desenvolvimento de atividades no ambiente de trilhas ecológicas e/ou interpretativas constituem-se em ferramentas fundamentais na busca por uma sociedade que reflita sobre a problemática ambiental de maneira crítica e que tais reflexões não se limitem apenas ao plano das ideias, mas que elas se tornem atitudes, materializadas em uma relação de valorização para com o meio.

\section{Agradecimentos}

À Fundação de Amparo à Pesquisa do Estado de São Paulo (FAPESP) pelo apoio financeiro à pesquisa e à Universidade Estadual Paulista "Júlio de Mesquita Filho", Campus Experimental de Rosana por tornar possível a graduação do autor. 


\section{Referências}

BECKER, H.S. Métodos de pesquisa em ciências sociais. São Paulo, HUCITEC, 1999.

BUTZKE, I.C; PEREIRA, G.R.; NOEBAUER, D. Sugestão de indicadores paraavaliação do desempenho das atividades educativas do sistema de gestão ambiental. SGA da Universidade Regional de Blumenau, FURB, 2007. Disponível em $<$ http://www.sf.dfis.furg.br/mea/remea/congress/artigos/comunicacao13.pdf >. Acesso em 27 de maio 2011.

CARVALHO, J.; BOÇÓN, R. Planejamento do traçado de uma trilha interpretativa através da caracterização florística. Revista Floresta, Curitiba, n. 1 (v. 34) p.23-32, jan./abr., 2004.

CASCINO, F. Educação Ambiental: princípios, história, formação de professores. São Paulo, Editora Senac São Paulo, 4ª ed., 2007.

DIAS, G.F. Educação Ambiental: princípios e práticas. São Paulo, Gaia, 9.ed., 2004.

FREIRE, P. Conscientização: teoria e prática da libertação: uma introdução ao pensamento de Paulo Freire. São Paulo, Costez \& Moraes, 1980.

GUIMARÃES, M. Educação ambiental: No consenso um embate. Campinas, Papirus, Coleção Papirus Educação, 2000.

Instituto Ambiental do Paraná (IAP). Plano de Manejo: Estação Ecológica do Caiuá. Paranavaí - PR, 1997.

LEFF, E. (coord.). A Complexidade ambiental. Tradução de Eliete Wolff. São Paulo, Cortez, 2003.

LEONARDI, M.L.A. A educação ambiental como um dos instrumentos de superação da insustentabilidade da sociedade atual. In: CAVALCANTI, C. Meio Ambiente, Desenvolvimento Sustentável e Políticas Públicas. São Paulo, Cortez, 2a ${ }^{\mathrm{a}}$. ed.,1999, p.391 - 408.

MAGRO, T.C.; TALORA, D.C. Planejamento e manejo de trilhas e impactos na flora. In: Congresso Nacional de Planejamento e Manejo de Trilha, I, 2006, Rio de Janeiro. Anais... Rio de Janeiro: Universidade Estadual do Rio de Janeiro. CD-ROM.

MAY, T. Pesquisa social: questões, métodos e processos. Porto Alegre, ArtMed, 2004.

MEDINA, N. M. Educação Ambiental: uma metodologia participativa de formação. - Petrópolis, Vozes, 1999.

PEREIRA, A.G.; BESSA, N.G.F. EA Formal e Não Formal praticado pelo PEAPA: Análise quanto aos procedimentos metodológicos utilizados. Revista eletrônica do Mestrado Educação Ambiental, v. 21, Julho/Dez., 2008. 
REIGOTA, M. O Que é educação ambiental. São Paulo, Brasiliense, Coleção Primeiros Passos, 2006.

RODRIGUES, V.A. (Coord.). A educação ambiental na trilha. Botucatu, UNESP- FCA, 2000.

SAMPAIO, S.M.V.; GUIMARÃES, L.B. Educação Ambiental: tecendo trilhas, escriturando territórios. Educação revista. n.3. vol. 25. Dez. 2009. p.353-368.

SERRANO, C.; BRUHNS, H.T. Viagens à natureza: Turismo, cultura e ambiente. SERRANO, Célia; BRUHNS, Heloisa Turini. (Orgs.). Campinas, Papirus, 1997. 